\title{
First steps: Parent health behaviours related to children's foot health
}

\author{
L Hodgson ${ }^{1}$, C Growcott $^{2}$, AE Williams ${ }^{2}$, CJ Nester ${ }^{2}$ and SC Morrison ${ }^{1}$ \\ Journal of Child Health Care
}

\begin{abstract}
Good foot health throughout childhood is important but remains poorly understood with few studies exploring this topic. The aim of this study was to define parents' knowledge, practices and healthrelated perceptions of children's feet. A qualitative design was adopted. Semi-structured, one-to-one interviews were carried out with parents of children aged five years and under, recruited from South East and North West of England. Interviews explored parents' views, beliefs and understanding of foot health in infancy and early childhood. Transcripts of the interviews were analysed using thematic analysis. Eighteen interviews were conducted. Seven themes were identified relating to (1) parents belief and knowledge about children's foot health; (2) how parents use and share foot health information; (3) activities for supporting foot health and development; (4) footwear choices, beliefs and influences; (5) the way they access health professionals; (6) the way they search for foot health information and (7) developing practice(s) to support parents. The study provides the first insight into how parents view foot health in early infancy and childhood. The findings highlight the key foot health beliefs important to parents, how they learn about and what influences their decision-making about caring for children's feet, the way parents receive and seek information, and how they access support for foot health concerns. The findings highlight the need for accurate, clear and consistent foot health messages, and the important role health professionals have in signposting parents towards reliable and informative sources on foot health.
\end{abstract}

\section{Introduction}

Good foot health throughout childhood is important and often a concern for parents and health professionals (Carli et al., 2012). Areas of concern include factors, which influence development of the foot (Chen et al., 2011), what (and when) shoes should be worn (Weiss et al., 1981), the development of children's feet (Carli et al., 2012; Yeo, James \& Ramachandran 2015), health burdens associated with long-term health needs (Fellas et al., 2017; Lim et al., 2015; Hendry et al., 2008) and functional problems (Aiyer \& Hennrikus 2014; Kothari et al., 2014). It has been established that the development of children's feet can be influenced by many factors (Chen et al 2011) and better efforts to understand this development will help support the promotion of good foot health throughout childhood. It is imperative to advance understanding around foot health literacy and develop parents' knowledge of important foot health information (Brodie et al., 2000; Penkala, 2012). Research suggests that developing and providing appropriate health information can increase knowledge, reduce decisional conflict and increase adherence with quality health advice, ensuring that good foot health strategies are developed early in the crucial stages of an infant's development (Longo, 2005; Penkala, 2012). To date this is an area of limited research with clear gaps in understanding about how parents explore children's foot health information, how they perceive their children's feet and the strategies employed when they have concerns.

Existing literature highlights that the way we find, assimilate and assess health information has become an emergent area of interest, and how parents search and understand online sources have seen increasing focus, (Barnhardt and Felter, 2004; Lederman et al., 2014; Shroff et al., 2017). Advances in technology and information sharing via websites, parent forums and social platforms like Twitter $^{\mathrm{TM}}$ and Facebook ${ }^{\mathrm{TM}}$ highlight the influence of online platforms and shifts in how parents access health information (Baker et al., 2003; Bernhardt and Felter, 2004; Cole et al., 2016; Hesse et al., 2005; Lederman et al., 2014; Pehora et al., 2015; Plantin and Daneback, 2009; Powell and Clarke, 2002; Rains and Donnerstein-Karmikel, 2009; Sarkadi and Bremberg, 2005; Wainstein et al., 2006; ). This change can pose challenges for health professionals if information is inaccurate or from out-of-date resources

${ }^{1}$ School of Health Sciences, University of Brighton, Brighton, UK
${ }^{2}$ School of Health and Society, University of Salford, Salford, UK

Corresponding author:

L Hodgson, School of Health Sciences, University of Brighton, Aldro Building, 49 Darley Road, Eastbourne, East Sussex BN20 7UR, UK

Email: L.Hodgson@Brighton.ac.uk 
(Pehora et al., 2015). The ease by which online health information can be shared raises questions about the accuracy of health information, the validity of sources and the consistency of the advice (Benigeri et al., 2003; Pehora et al., 2015). Many factors influence the assimilation of health information and barriers to health literacy are important considerations (Lederman et al., 2014; Penkala, 2012). Lower social determinants, such as literacy skills and educational background, could affect how parents evaluate sources of foot health information and how information is utilised (Penkala, 2012). The aim of this study was to explore/define parents' current knowledge, practices and health-related perceptions of children's feet.

\section{Method}

Participants and recruitment

Purposeful sampling was adopted to recruit a diverse sample of parents who cared for an infant or child aged five years and under (Palinkas et al., 2015). One parent was invited to participate on behalf of the family unit and gender, marital status, socio-economic, ethnic background were noted. All participants confirmed that their child's development was typical with no existing foot problems.

Our recruitment approach included dissemination of the study via Twitter ${ }^{\mathrm{TM}}$, Facebook ${ }^{\mathrm{TM}}$ and the project website (Great Foundations - www.greatfoundations.org.uk). Leaflets were disseminated in the local areas, and local nurseries and parent networks were also contacted. Recruitment was undertaken in two localities, in South East and North West England.

\section{Design}

A qualitative design was adopted using semi-structured, one-to-one interviews. The interview schedule was designed to elicit information from participants about a) factors informing foot health knowledge, beliefs and approaches; b) current practices for accessing foot care/foot health services; c) messages received and considered important about foot health and footwear advice and d) information being sought about paediatric foot health. These questions were formulated from the results of an ongoing phase of work mapping and investigating online resources available to parents, health professionals and commercial organisations relating to children's foot health.

\section{Procedure}

Data collection was undertaken from March to July 2017. Parents were invited to participate in a faceto-face, or telephone interview and the research team adopted a flexible, time-efficient approach to suit parents' schedules and using their preferred communication option (Novick, 2008; Sturges and Hanrahan, 2004). Interviews lasted between 30 and 60 minutes. Informed written and verbal consent was obtained prior to interviews. If written consent was not returned prior to a telephone interview, audio-recorded verbal consent was obtained prior to interviews commencing. Two researchers conducted the interviews using the same recruitment and interview protocol to minimise disparities.

Data management and analysis

Interviews were audio recorded, allocated a unique identifying number and transcribed verbatim. Transcripts were subject to participant verification to ensure trustworthiness (Morse et al., 2002). Following verification, interview transcripts were uploaded to NVivo [11.4.3] and thematic analysis undertaken (Braun and Clark 2006; Kornbluh, 2015). This approach commenced with the researcher (lead author) with data familiarisation by reading the full transcripts and listening to recordings. Coding of the data and conceptual note-taking was then undertaken. To support analytical rigour, a second researcher (second author) independently reviewed the data and generated codes. Code patterns were developed and refined until the initial themes and subthemes were agreed. The table of themes and subthemes, discrepancies and rationales for the themes were discussed with the research team (other authors not involved in the data collection and analysis) to refine to gain further confirmability of the final themes and add further transparency and credibility to the theme development process.

Ethical approval

Ethical approval was provided by the School of Health Sciences Research Ethics Panel, University of Brighton. 
Table 1. Demographic characteristics of parents interviewed $(n=18)$

\begin{tabular}{|c|c|}
\hline Characteristic & Frequency $(n)$ \\
\hline \multicolumn{2}{|l|}{ Gender } \\
\hline Female & 15 \\
\hline Male & 3 \\
\hline \multicolumn{2}{|l|}{ Age Range } \\
\hline 24 years and younger & 1 \\
\hline $25-29$ & 1 \\
\hline $30-35$ & 8 \\
\hline $36-41$ & 8 \\
\hline \multicolumn{2}{|l|}{ Region } \\
\hline South East England & 8 \\
\hline East of England & 1 \\
\hline East Midlands & 1 \\
\hline North West England & 8 \\
\hline \multicolumn{2}{|l|}{ Children under 5 years } \\
\hline $\begin{array}{l}\text { One child aged } 5 \text { and under } \\
\text { More than one child ages } 5 \text { and younger } \\
\text { Educational level }\end{array}$ & $\begin{array}{l}12 \\
6\end{array}$ \\
\hline A-Level & 5 \\
\hline Undergraduate & 9 \\
\hline Postgraduate & 3 \\
\hline Did not answer & 1 \\
\hline \multicolumn{2}{|l|}{ Employment status } \\
\hline Part-time & 6 \\
\hline Full-time & 5 \\
\hline Unemployed & 1 \\
\hline Stay at home parent & 4 \\
\hline Self employed & 1 \\
\hline Did not answer & 1 \\
\hline \multicolumn{2}{|l|}{ Relationship status } \\
\hline Married & 14 \\
\hline Living with partner & 1 \\
\hline Single & 2 \\
\hline Did not declare & 1 \\
\hline \multicolumn{2}{|l|}{ Nationality } \\
\hline White British & 17 \\
\hline White German & 1 \\
\hline
\end{tabular}

\section{Results}

Participant characteristics

Eighteen interviews were conducted and participant characteristics are reported in Table 1 . The sample was predominately represented by white British (17), married (14), women (15) and over half of the sample (12) were in full/part-time employment or were self-employed. Twelve parents had one child aged five years and or younger while six had two children aged five years or below.

Seven overarching themes were identified concerning what was important to parents when thinking about children's foot health, foot health information and their practices in relation to foot care. Findings also offered views on current health-seeking behaviours, guidance sought from health professionals and parents' perspective about the role footwear companies have in sharing foot health information. Findings are illustrated with verbatim quotes accompanied by the participant's study code in brackets (e.g. PE1, PS2).

\section{Theme 1: Parents Beliefs and Knowledge about children's foot health}

In most interviews, parents did not view foot health as an important health concern and believed they had little knowledge or lacked awareness about children's foot health '...It is terrible to say, but I don't really know' (PE11). When parents were prompted to think about feet and the actions they take daily towards looking after their own children's feet, parents were able to identify four key areas that they felt were important to ensuring that good foot health practices were being observed: well-fitting footwear, hygiene was observed, maintaining toenail care, and generally observing children's feet to ensure healthy growing feet. It was also recognised that parents often did not always know the reasons 
underpinning their beliefs, and why they felt these were priorities for them. The majority of parents recognised neglecting foot care could potentially impact on children's overall health and wellbeing.

Never really think about it...no it's not a noisy, dirty part of the body, it's one that you kind of forget about, because everything else is a bit more urgent. (PS2)

\section{Theme 2: Sharing foot health information}

The majority of parents acknowledged that discussing and sharing foot health information was not a common occurrence and used phrases like 'we don't really discuss feet.' (PS7). On the occasions that foot health concerns were discussed, topics often arose from casual conversation that may have prompted a question or observation about foot health. Topics discussed were more common foot concerns, for example, athlete's foot, footwear and measuring, nail cutting and verrucae. Parents appeared to share or ask for information from other parent peers for reassurance purposes. In particular, if a method, treatment or piece of advice worked well for their children, especially if advice was given from experienced parents with older/multiple children. These appeared to be rooted in their own experiences or inherited from family members.

I would probably also ask people who have babies of a similar age and possibly ask my mum is this normal, has this happened before, is this supposed to happen? (PS2)

Don't know where. My mum probably told me...I think a lot of I find parenting is just how you've been brought up. You just carry it on, don't you, I think? (PE10)

So you do tend to yeah, listen to, you would listen to parents especially if they've got more than one child and they've done it as well. (PE8)

\section{Theme 3: Supporting healthy development}

There were many activities that parents instinctively undertook to support their child's development, such as encouraging tummy time, encouraging walking and allowing time without shoes. Parents felt they were supporting their child's foot health needs. However, they were not always confident in identifying what should be done or knowing if this was suitable. One participant said:

I think it's almost subconsciously you just think they generally look ok, um, she can get up and get down ok, um sort of visually there's nothing wrong I don't think, but then again you don't know what to look out for. (PS6)

\section{Theme 4: Footwear choices, beliefs and influences}

Well-fitting footwear was an important belief among parents and they often sought out leading footwear companies to ensure that their child had suitable and comfortable footwear. The information parents received about footwear appeared to be influenced by the information that they received during their experiences with footwear companies, family advice and peers. Leading footwear companies were thought to influence parents purchasing habits due to parent's familiarity with them and their long-standing presence. Many parents highlighted their own childhood memories of being taken to get their feet measured for school shoes and this was seen to influence parenting practices. Other common factors were recommendation by peers:

My parents got our shoes from there. And it seems like, it feels like a bit of an institution for children's shoes now. And I suppose it is a brand that I expect to be good quality and that's their reputation, certainly amongst everybody I know. (PS4)

Just because it's where everyone goes for shoes, yeah! (PS1)

Parents also noted that they chose leading shoe companies because there were limited options to have their children's feet measured. Even though well-fitting footwear was seen to be important to parents, there were many factors which influenced their decision-making about where, how and what shoes to buy their children. Shoe companies that offered fitting services were important for some parents especially if their children would be wearing the shoe for long periods of time "I always buy, 
um we always go and get them fitted correctly and buy the better shoes because I think if they're, if they're in them for the amount of time' (PE8). However, cost was an important factor. Shoes, which were seen to be less important, for example, trainers or beach shoes, would often be purchased from cheaper outlets like supermarkets or sport shops. Parents often sacrificed fitting services/advice when choosing cheaper 'off the peg' shoes or bought shoes in bigger sizes to last longer.

Yeah and in that scenario obviously there's no-one in [High-street fashion store] that can advise on the fit of a shoe so then it's down to us to make that decision and copy what the [footwear company] lady did earlier. Yeah, so we'll see how it - he seems to get on okay with them. I don't think it will cause any damage, but you know on the whole I would prefer both of them to have [footwear company] shoes. (PE1)

When it came down to price, that's what swayed them, they wanted a bigger, they wanted a bigger size because they thought oh that will save me thirty quid in three months-time and these shoes will last them for six months rather than just three months. (PE2)

One participant, from a single parent household echoed similar concern. However, unlike other parents in the study have indicated purchasing school shoes from cheaper retailers that do not offer a fitting services or advice.

school pumps from [High-street fashion store]. I think from [High-street fashion store] they were only like f2. I suppose because I'm on such a budget myself with being on my own we have to look at cheaper alternatives. I think budget does play a lot of things on shoes and things. (PS8)

\section{Theme 5: Accessing health professionals}

Given our sampling strategy, there were few parents that had accessed health professionals with a foot concern but parents noted that feet and foot health did not appear to be obvious consideration during early infancy health checks. Parents noted that they were unsure of health professional's roles in relation to children's feet and experienced discrepancy in advice or information. Although parents did not typically access a health professional with a foot concern, they felt that there could be inconsistencies with advice being relayed to parents, for example, between pharmacists and GP for over-the-counter skin treatments.

I rang a chiropodist [regarding a verrucae] and she said there's nothing I can do for kids under the age of sixteen. Then the pharmacist says right at the age of six we're not allowed you need to go to the doctor. The doctor did say to me we won't freeze them on a child. Instead you get this little bottle of acid [from the pharmacist] to get rid of them, so that is what we did. (PE8)

Parents believed they would not know which health professionals to access and would rely on their GP and/or health visitor to refer their child to the appropriate services. 'if I was due a health visitor's appointment l'd probably wait and ask a health visitor or ask the clinic.' (PS2). In addition, parents also remarked about not wanting to bother busy health professionals and take up their time; therefore, this could prompt parents to access other sources of information before visiting a health professional. Parents noted that they were unclear on what defined good foot health practices and remarked that they did not feel foot health messages were clearly conveyed.

I think um today, you're kind of encouraged to... find advice online before you go and see your doctor, that seems to be, it always seems to be very hectic at the doctors, and it's a nightmare trying to get any kind of attention I suppose. (PE2)

Nothing's been flagged up to me to the sort of things to look out for or good practice or thing like that. (PE9)

\section{Theme 6: Searching for foot health information}

Some parents noted that they were often prompted to look up information following visits to a health professional and parents looked to online sources to verify, understand options for self-treatment and seek reassurance. The origin of the sources was important to parents but they indicated that it was 
difficult to get trustworthy and in-depth foot health information, specifically related to children. They described that health information online was poor, lacked detail and did not provide consistent messages. Parents highlighted that good judgement and common sense were needed to isolate potential information sources and awareness of the sources, and internet site was important when assessing whether to follow any advice found. Parents were very aware and cautious of 'anecdotal' information in online parent forums.

unless you kind of like specifically go and search for these kind of things, it doesn't really, it doesn't really say oh you know, this is what you should be looking out for your children's foot health. (PE2)

I did google it, have a look and that just backed up what the chiropodist said cos after what she said I googled it just to check cos I thought if it is something I can get over the counter then I'll do it that way although I googled it to make sure it wouldn't be anything harmful. (PE8)

[online parent forum] and that sort of thing... I found that does more harm than good because there had been a lot of information saying she's going to die or have some brain damage. I think people, in my opinion, people tend to only post something if it's been a major or traumatic event. You don't tend to say oh my child had severely pronated feet, but she's fine now. You see less of that than oh my god it was an absolute disaster, because people are obviously quite highly fuelled and it's been an emotional experience. (PE3)

I find I get more confidence from things like that, I mean the NHS is great but for, definitely for children's kind of foot related things there wasn't hardly anything there. (PE2)

\section{Theme 7: Developing practice(s) to support parents}

Parents noted the difficulties they had in accessing good foot health information. Parents were consistent in identifying that it could be difficult to identify the correct health professional or services to access first for children's foot health concerns, but would more often than not use their GPs as a first point of contact. Increased visibility of concise foot health messages appeared important, providing varying formats and platforms. Improved signposting and education of the appropriate services/information to access could increase parents' opportunities and improve awareness of trustworthy information needed to support children's foot health and development.

...clear information when it's when you're looking for it, making it easily accessible, cos jargon isn't going to work for many people, some people love a bit of science, but most people don't. (PE7)

I know different people have said, 'Oh, you shouldn't encourage them to stand' because when they're too small, because it's not good for their hips and things, but then I've heard that that's actually an old-wives' tale and that doesn't matter. So, it would be interesting to have almost the facts laid out. (PS8)

...I'd rather be given, or at least you know pointed in the right direction, as a Mum or Dad you kind of have to look at, look for it yourself and there's no real direction where to go. (PE2)

\section{Discussion}

The study advances understanding of parents' behaviour in searching for information, views and literacy around children's foot health. It depicts how key health messages are learnt and used to support foot health in early childhood, highlighting what parents believe is important and the level of priority which foot health is given amongst children's health and wellbeing needs. It also provides an indication of how parents understand foot health messages and how this influences their decision making.

There was a common belief that they did not know anything about feet or foot health. However, this study highlighted that there are many basic activities and strategies that parents employ to support healthy foot care practices, even if they were unaware that these activities encouraged healthy foot development in their children (e.g. fitted shoes, basic hygiene and supporting development). In addition, this study indicated that many of these foot health strategies were based 
on inherited wisdom often influenced and reinforced by parents own lived experiences or childhood memories.

Influential messages were often received from passive information sources or promoted by commercial organisations, which influenced choices about children's footwear. Parents reported choosing leading high street retailers to buy children's shoes and having their children's feet measured, because it is what they did as children as well as it being promoted by footwear companies. The passive learning of a variety of supportive strategies demonstrated in this study suggests that, whilst children's feet were rarely talked about, strategies to ensure the promotion of foot health, and footwear fit, remain important for supporting development across childhood. However, these messages could possibly be harder for parents trying to accommodate children's needs when they have complex foot health conditions which might impact foot development and walking. The study highlights that cost still remains an influencing factor when choosing where to buy children's shoes, with some parents acknowledging the difficulties of keeping up the demands of their child's changing footwear needs. Many sacrificed fitted footwear services choosing to purchase footwear from cheaper retailers with no available fitting services.

Parents health information seeking behaviours were often prompted by changes in their own child's foot health making their actions more reactive than preventative. This study highlighted that parent's engagement with health professionals appeared to occur in varying capacities with foot health being an infrequent reason for access to health professionals and it did not appear to feature during early health check-ups. This could explain the low priority foot health is given by parents and what they determine to be a health priority (Arora, 2003). In the few interactions that were discussed, parents identified concerns about inconsistent advice being relayed to parents and the conflict between professionals. There was a lack of understanding as to the roles of different health professionals, and how they would be helpful if they had a concern. This meant that parents relied on gateway health professionals such as GPs and health visitors to guide them to provide treatment or referral. In circumstances where parents did seek out foot health advice, they received little or inconsistent information which might explain why, when needed, parents sought information or visited internet sources. It is possible these impact on the level of concern or consideration that parents may give foot health. Not wanting to bother busy health professionals with questions could be a further motivating factor for parents to seek information from alternative sources, to clarify and understand terminology, treatment or diagnosis made (Benigeri., 2003; Lederman et al., 2014; Penkala, 2012).

There are well-established health information/campaigns with clearly defined health advice to improve the health and wellbeing of children. These campaigns have an established presence in health agendas and continue to cultivate and reinforce their messages on a local and national level. Strong campaigns include dental care, obesity and getting children physically active, which are preventative health measures to reduce childhood inactivity, obesity, and to ensure children are healthy, pain free and can fulfil an active life to support health and wellbeing (Public Health England., 2016; Childhood). The success of these national campaigns has created behaviour change, improved awareness and increased adherence to health strategies supporting overall health (Friel et al., 2002; Huhman et al., 2005). It could be suggested raising the awareness of foot health messages and the importance of good foot health in early childhood could contribute to reducing factors, which can impact on the development of the foot, concerns about footwear and any health burdens associated with long-term health needs ensuring that children experience healthy active lifestyle that extends beyond childhood (Lim et al., 2015).

Parents felt they had to use common sense to determine and cherry-pick information as it could be challenging to ascertain the accuracy or usefulness of the information. Parents reported online forums to be of emotional-based content and needed to be 'cautious of' due to little factual content. Emotional factors can influence how well an individual can assess if the information is useful or the relevance of its content, which can lead to diminished judgement and increase the use of misinformation (Lederman et al., 2014), and possibly difficulties in recalling information, and misreporting/posting information. However, in this study, parents appeared to have a high level of awareness of the potential risks associated with using internet-based information and did not appear to make emotionally influenced foot health decisions. Parents still engaged in actively reading discussion trails, and they would follow potential information leads to help guide, reassure or indicate if they needed to be concerned and seek further action and advice. The parents in this study did not 
report any foot health concerns and, as such, viewed this as a low priority and it impacted little on daily life. Whilst the development of the foot remains a common cause of anxiety for many parents (Yeo et al 2015) this didn't emerge within our sample. Improving the communication of foot health information and foot health education could improve the clarity of the way health messages are being relayed to a parent audience and improve general access to health services, health information, improve health outcomes and improve general foot health knowledge (Nutbeam, 2008).

\section{Limitations of the study}

Whilst the results of this study offer us a rich perspective of parent's approaches to their children's foot health, it is important to acknowledge that the focus of this work was on the typical development of the foot. Parents of children that present with pre-existing complex foot conditions may value, search, comprehend and use information differently. Further research would need to be carried out to characterise and understand if these experiences differ and how this impacts on their decisionmaking and how this influences their engagement with health professionals, services and commercial companies. The study findings are representative of a small parent sample, which indicated socioeconomic factors are important. Further work to explore these factors needs to be carried out, with a wider parent demographic to fully understand the impact on parents' consideration of their children's foot health.

\section{Conclusion}

This study provides insight into parents understanding of children's foot health. Although parents viewed foot health as a low priority, the study highlights that parents' engagement with their children's feet also demonstrated beliefs of the importance of maintaining foot health in early childhood. Parents were influenced by multiple of factors which included family and friends, footwear companies, information from the internet and health professionals which supported parent's beliefs and often determined how they approached and managed foot care in young children. It was not always clear to parents what the important issues about children's feet were. Parent information-seeking behaviours and interaction with health professionals did not always lead parents to easy and consistent information. The findings from this study highlight that parents want accurate, accessible foot health information and that health professionals have a key role in disseminating and signposting parents towards sources of information that offer clear, consistent, and reliable advice.

\section{Funding}

The Dr William M Scholl Unit of Podiatric Development.

\section{References:}

Aiyer, A., Hennrikus, W., (2014) Foot pain in the child and adolescent. Pediatrics Clinic of North America. 61 (6):1185-205, https://doi.org/10.1016/j.pcl.2014.08.005

Arora, NK (2003) Interacting with cancer patients: the significance of physicians communication behaviour Social Science Medicine 2003, 57,791-806 https://doi.org/10.1016/S0277-9536(02)00449-5

Baker, L, Wagner, TH, Singer, S (2003) User of the Internet and email for health care information: results from a national survey Journal of the American Medical Association, 289, 2400-2406 DOI:

$\underline{10.1001 / j a m a .289 .18 .2400}$

Bernhardt, JM, Felter, EM (2004) Online paediatric information seeking among mothers of young children: results from a qualitative study using focus groups. Journal of Medical Internet Research 6: e7 doi:10.2196/imir.6.1.e7

Benigeri, M, Pluye, P (2003) Shortcoming of health information on the internet. Health Promotion International 18 (4):381-386 https://doi.org/10.1093/heapro/dag409

Braun, V, Clarke, V (2006) Using thematic analysis in psychology. Qualitative Research Psychology 3:77101. https://doi.org/10.1191/1478088706qp063oa 
Brodie, M; Flournoy, R.E; Altman, D.E; Blendon, R.J; Benson, JM (2000) Health information, the internet, and the digital divide. Health Affairs 19(6): Nov-Dec 2000 DOI: 10.1377/hlthaff.19.6.255

Carli, A, Saran, N, Kruijit, J, Alam, N, Hamdy, R (2012) Physiological referrals for paediatric musculoskeletal complaints: A costly problem that needs to be addressed. Paediatric Child Health Nov 17(9): e93-e97 https://doi.org/10.1093/pch/17.9.e93

Chen, K. C., Yeh, C. J., Tung, L. C., Yang, J. F., Yang, S. F., Wang, C. H. (2011). Relevant factors influencing flatfoot in preschool-aged children. European Journal of paediatrics 170(7): 931-936. DOI: 10.1007/s00431-010-1380-7

Cole, J., Watkins, C., Kleine D., (2016) Health Advice from internet discussion forums: how bad is dangerous? Journal of Internet Medical Research 18 (1):e4. DOI:10.2196/jmir.5051

Fellas, A., Hawke, F., Santos, D., Coda, A., (2017) Prevalence, presentation and treatment of lower limb pathologies in juvenile idiopathic arthritis: A narrative review. Journal of Paediatric Child Health 53 (9): 836-840, doi:10.1111/jpc.13646

Friel, S, Hope, A, Kelleher, C, Comer, S, Sadlier D (2002) Impact of an oral health intervention amongst primary school children in Ireland. Health Promotion International 17(2): e119

https://doi.org/10.1093/heapro/17.2.119

Hendry, G., Gardner-Medwin, J., Watt, GF., Woodburn, J., (2008) A survey of foot problems in juvenile idiopathic arthritis. Musculoskeletal Care. 6 (4): 221-32 https://doi.org/10.1002/msc.134

Hesse, B.W; Nelson, D.E; Kreps, G.L; Croyle, R.T; Arora, N.K; Rimer B.K and Viswanath, K (2005) Trust and sources of health information: The impact of the internet and its implication for health care providers: Findings from the first health information national trends survey. Journal of Archive Internal Medicine 165(22): 2618-2624. DOI:

$\underline{10.1001 / \text { archinte.165.22.2618 }}$

Huhman, M, Potter, LD, Wong, FL, Banspach, SW, Duke, JC, Heitzler, CD (2005) Effects of a mass media campaign on increase physical activity among children: Year 1 results of the VERB campaign. Journal of the American Academy of Pediatrics 116(2): e277 www.pediatrics.org/cgi/doi/10.1542/peds.2005-0043

Kornbluh, M (2015) Combatting Challenges to Establishing Trustworthiness in Qualitative Research, Qualitative Research in Psychology, 12(4): 397-414, DOI: 10.1080/14780887.2015.1021941

Kothari, A., Stebbins, J., Zavatsky, AB., Theologis, T., (2014) Health related quality of life in children with flexible flatfeet: a cross-sectional study. Journal of Children's Orthopaedics, 8 (6): 489-496, https://dx.doi.org/10.1007\%2Fs11832-014-0621-0

Lederman, R, Fan, $\mathrm{H}$ and Smith, S (2014) Who can you trust? Credibility assessment in online health forums. Health Policy and Technology 3: 13-25 DOI: 10.1016/j.hlpt.2013.11.003

Lim, Polly QX., Shields, N., Nikolopoulos, N., Barrett, JT., Evans, AM., Taylor, NF, Munteanu, SE., (2015) The association of foot structure and footwear fit with disability children and adolescents with Down Syndrome. Journal of Foot and Ankle Research. 8:4 https://dx.doi.org/10.1186\%2Fs13047-015-0062-0

Longo, R (2005) Understanding health information, communication, and information seeking of patients and consumers: a comprehensive and integrated model. Health Expectations 8:189-194 https://doi.org/10.1111/j.1369-7625.2005.00339.x

Morse, JM, Barrett, M, Mayan, M, Olson, K, Spiers, J (2002) Verification strategies for establishing reliability and validity in qualitative research. Internal Journal of Qualitative Methods 1 (2) https://doi.org/10.1177\%2F160940690200100202 
Novick, G (2008), Is there a bias against telephone interviews in qualitative research. Residential Nurse Health, August, 31(4): 391-398 DOI: 10.1002/nur.20259

Nutbeam, D (2008) The evolving concept of health literacy. Social Science and Medicine, 67: M2072-2078. http://Doi:10.1016/j.socscimed.2008.09.050

Palermo TM, and Lewandowski-Holley A, (2013) The Importance of Family Environment in Pediatric Chronic Pain. Pediatrics 167(1): 93-94 DOI: 10.1001/jamapediatrics.2013.428

Palinkas, LA, Horwitz, SM, Green, CA, Wisdom, JP, Duan, N, Hoagwood, K (2015) Purposeful sampling for qualitative data collection and analysis in mixed method implementation research. Adm Policy Ment Health. 2015 Sep; 42(5): 533-544. DOI: 10.1007/s10488-013-0528-y

Pehora, C; Gajaria, N; Stoute, M; Fracassa, S; Serbale-O'Sullivan, R; Matava, C.T (2015) Are parents getting it right? A survey of parents' internet use for children's healthcare information. Interactive Journal of Medical Research 4(2): e12 DOI: 10.2196/ijmr.3790.

Penkala, S (2012) Health literacy: Implication for shoe choices promoting foot health in children. International Journal of Health, Wellness and Society 1 (4): 88-97 DOI: 10.1155/2012/490647

Plantin L, Daneback K (2009) Parenting information and support on the internet. A literature review of research on parents and professionals online. BMC Family Practice 10:34 DOI: 10.1186/1471-2296-1034

Powell, J, Clarke, A (2002) The WWW of the World Wide Web: Who what and why? Journal of Medical Internet Research 4: e4 DOI:10.2196/jmir.4.1.e4

Public Health England (2016) Delivering supervised toothbrushing for two, three- and four-years olds in early years settings "Smiles4Children" December 2016

https://www.foundationyears.org.uk/files/2016/12/Toothbrushing-Report.pdf (accessed 29th August 2018)

Rains, A.S, Donnersteinb-Karmikel, C (2009) Health information-seeking and perception of websites credibility: Examining web-use orientation, message characteristics, and structural features of websites. Journal of Computer in Human Behaviour 25: 244-553 http://doi:10.1016/j.chb.2008.11.005

Sarkadi A, Bremberg S (2005) Socially unbiased parenting support on the internet: a cross-sectional study of users of a large Swedish parenting website. Child Care Health Development 31: 43-52 DOI: 10.1111/i.1365-2214.2005.00475.x

Shroff, PL; Hayes, RW; Padmanabhan, P and Stevenson, MD (2017) Internet usage by parents prior to seeking care at a paediatric emergency department: Observational study. Journal of Medical Research 2017 Jul-Dec, 6 (2): e17 DOI: $10.2196 /$ ijmr.5075

Sturges, JE, Hanrahan KJ (2004) Comparing telephone and face-to-face qualitative interviewing: A research note. Qualitative Research 4:107-118 DOI: 10.1177/1468794104041110

Van Der Gugten, AC, de Leeuw, RJRRJ, Verheij, TJM, van der Ent, CK (2016) E-health and health care behaviour of parents of young children: a qualitative study. Scandinavian Journal of Primary Health Care. 34(2): e135-142. http://dx.doi.org/10.3109/02813432.2016.1160627

Wainstein, BR, Sterling-Levis, K, Baker, SA, Taitz, J, Brydon, M (2006) Use of the internet by parents of paediatric patients. Journal of Paediatric and Child Health 42, 2006: 528-532 https://doi.org/10.1111/j.1440-1754.2006.00916.x

Weiss, J, De Jong, A, Packer, E. and Bonanni, L., (1981). Purchasing infant shoes: attitudes of parents, paediatricians, and store managers. Paediatrics, 67(5): 718-720. 
Yeo, A., James, K., Ramachandran, M., (2015) Normal lower limb variants in children. BMJ 2015,351:h3394, https://doi.org/10.1136/bmj.h3394

11 